DOI 10.37882/2500-3682.2021.08.15

\title{
ЛЕОПОЛЬДО СЕА И РОЖДЕНИЕ ИНТЕЛЛЕКТУАЛЬНОЙ СРЕДЫ В ЛАТИНСКОЙ АМЕРИКЕ (40-Е - НАЧАЛО 50-Х ГГ. ХХ В.)
}

\section{LEOPOLDO ZEA AND THE BIRTH OF AN INTELLECTUAL COMMUNITY \\ IN LATIN AMERICA (40S - EARLY 50S OF THE XX CENTURY)}

\section{O. Masalova}

Summary: This article is devoted to an almost obscure problem, both in Russian and in foreign practice, the problem of the formation of a unified Latin American intellectual environment in the post-war period. Most of the studies are based on the material of the 60-80s of the twentieth century, more formed, methodologically verified, having clear regional differences. In this case, we are talking about the moment of the formation of Latin American humanitarian socio-cultural practice and the role of a very famous Mexican thinker in this process in the future.

Keywords: culture, Latin America, Leopoldo Zea, dialogue of cultures, scientific heritage, intellectual community.

\author{
Масалова Ольга Алексеевна \\ Дочент, Казанский (Приволжский) федеральный \\ университет \\ omasalova@mail.ru
}

Аннотация: Данная статья посвящена практически неосвещаемой проблеме, как в российской, так и в зарубежной практике, - проблеме формирования единой латиноамериканской интеллектуальной среды в послевоенный период. Большинство исследований опираются на материал 60-80-х гг. XX в., более сформированный, методологически выверенный, имеющий четкие региональные отличия. В данном случает речь идет о моменте становления латиноамериканской гуманитарной социокультурной практики и о роли в будущем очень известного мексиканского мыслителя в этом процессе.

Ключевые слова: культура, Латинская Америка, Леопольдо Сеа, диалог культур, научное наследие, интеллектуальная среда.

ческую информацию (дата рождения, годы и место обучения, занимаемые им должности), которые содержатся в любой энциклопедической статье $[3,77]$.

Определенную информацию (очень незначительную) о детстве и о раннем периоде научно-исследовательской работы Л. Сеа можно почерпнуть из его эссе «Интеллектуальная автобиография (написанная от третьего лица)» [4] и из введения к его монографии «Новый мир в вызовах нового тысячелетия» [5].

Его научная деятельность начинается в 1942 г., когда он начинает читать курс «Введение в философию» в Национальной Подготовительной Школе. В связи с реформой университетского образования в 1944 г. молодой исследователь, прислушавшись к советам своего учителя, мексиканского философа Хосе Гаоса, берет на себя обязанности заведующего кафедрой философии истории Факультета философии и литературы Национального Автономного университета Мексики (УНАМ).

Практически все исследователи научной биографии Л. Сеа приходят к выводу, что весь академический путь можно разделить на три крупных этапа:

І этап - 40 - конец 50-х гг. XX в.

II этап - конец 50-х гг. - середина 70-х гг. XX в.

III этап - середина 70-х гг. XX в. - 2004 г. [6] 
Коллега Л. Сеа по «философии освобождения» Э. Дуссель в своей статье «Проект философии латиноамериканской истории: Леопольдо Сеа» [7], придерживаясь принципа выделения в творчестве ученого трех этапов, все же дает иную периодизацию. Периодизация, данная Э. Дусселем, основана на тех исследовательских проблемах, которые находились в центре внимания Л. Сеана каждом этапе: проблемы освобождения (І этап), проблемы американской истории (II этап), проблемы универсального (III этап).

В данной публикации будет поддержан доминирующий вариант периодизации научной биографии.

Исследуемый хронологический период приходится на первый этап и характеризуется интересом профессора к истории идей в Латинской Америке. Именно в это время он работает над темой своего диссертационного сочинения «Позитивизм в Мексике». М. Каррера в исследовании «Леопольдо Сеа и латиноамериканская философия» приводит мнение многих авторов обращавшихся к латиноамериканской философской традиции о том, что вплоть до сегодняшнего дня его диссертационное сочинение «Позитивизм в Мексике», защищенной в 1942 г., является «лучшей работой по истории идей в Латинской Америке» [8].

Сороковые годы XX в. стали очень насыщенными для молодого ученого (частично мы говорили об этом выше): в 1943 г. он становится преподавателем философии в УНАМе и в том же году публикует свою первую монографию, написанную на основе диссертации. Уже в 1944 г. Л. Сеа становится доктором философии и в том же году он издает свой второй монографический труд «Расцвет и упадок позитивизма в Мексике», ставшей действительным научным «дебютом» $[9,8]$.

Ранее уже говорилось о том, что в 1944 г. он становится заведующим кафедрой философии истории в УНАМ. По совету Х. Гаоса, своего научного руководителя, Л. Сеа продолжает разрабатывать ранее начатое в области истории идей (изучение позитивизма), но не замыкается в рамках одной страны, а расширяет поле своих исследований до самых крайних пределов всего латиноамериканского региона.

После знакомства с Уильямом Беррианом, профессором Гарвардского университета и председателем Фонда Рокфеллера, Л. Сеа выигрывает стипендию на 1945-1946 гг. с полугодовой стажировкой в США и годовой работой в архивах и библиотеках различных латиноамериканских стран.

Именно это первое путешествие в США по маршруту Вашингтон - Нью-Йорк - Чикаго наглядно показало Л. Сеа на его собственном примере, какое место занима- ет мексиканец / латиноамериканец в странах Запада: автобусы с табличками «Только для белых!» и «Только для цветных!», гостиницы для мексиканцев, отношение как к обслуживающему персоналу вне зависимости от того, кем он является.

Итогом стажировки стала публикация в 1949 г. работы «Два этапа развития мысли в Латинской Америке».

Главный вопрос, который волнует молодого исследователя: возможно ли говорить о существовании и специфике латиноамериканской философской школы как таковой?

Во время своей стажировки в различных странах Латинской Америки (об этом упоминает только М. Каррера) Л. Сеа оказывается активным участником выступлений и манифестаций, вызванных социально-политическими потрясениями в этих регионах. В 1945-1946 гг. он участвует в манифестациях в Буэнос-Айресе против ссылки Х. Перона и в манифестациях в Рио-де-Жанейро против режима Варгаса, в различных политических акциях, проходивших в Перу и Венесуэле (о чем свидетельствует и сам Л. Сеа, и испанский историк М. Каррера).

Таким образом, в 40-е гг. XX в. формируется не только научная база для изысканий молодого и перспективного исследователя, но и происходит становление его политической позиции.

Также этот этап ознаменовался созданием в 1947 г. «Комитета по истории идей в Латинской Америке», который было поручено возглавить Л. Сеа. «Основная задача Комитета должна была состоять в подготовке и публикации «Истории идей» каждой из латиноамериканских стран... Эти работы осуществлялись в сотрудничестве с рядом видных специалистов, с большинством из которых меня уже связывали личные контакты, установленные за время моего путешествия по Латинской Америке в 1945-1946 гг.» [10, 12], - вспоминает Леопольдо Сеа.

Он установил дружеские и творческие отношения «не только с Франсиско Ромеро и его братом Хосе Луисом Ромеро, но и целой группой аргентинских ученых. В Уругвае он общался с Вас Ферейро и установил дружеские отношения с Артуро Ардао. В Бразилии он был немного знаком с Жуаном Круз Кошта. В Чили - с Энрике Молинья. В Боливии - с Гильермо Франковичем, в Перу - с Франсиско Миро Кессада, в Эквадоре - с Бенджамином Карроном, в Колумбии - с Германом Арсиньегасом и Данило Крус Велесом, в Венесуэле - с Мариано Пикон Саласом и многими другими[4, 12-13].

Испанский исследователь Х.Е. Биаджини приводит мнение другого ученого, Э. Дэвиса, о значении деятельности Л. Сеа в Комитете. В качестве руководителя он 
создавал условия для серьезной исследовательской работы членов Комитета, предоставляя источниковый материал, завязывая контакты в интеллектуальной среде в каждой стране Латинской Америки, поощряя научную коммуникацию и координируя латиноамериканское гуманитарное сообщество [11].

В 1947 г. создается творческая группа «Гиперион» [12, 196] (преобразовалась в дальнейшем в постоянно действующий семинар по истории общественной мысли в Латинской Америке), одним из лидеров которой был Л. Сеа. «Именно этот момент является отправной точкой оформления его методологии. Об этом говорят Г.Г. Кромбет, ВЛ. Абушенко, Л.А. Керретеро, Х.А. Абеллян, М. Каррера, А. Костаньон, Х.Г. Мартини и мн.др.»[3, 85]

Данный этап связан с активной преподавательской деятельностью Л. Сеа, который читает лекции не только в УНАМ, но и по приглашению Франсиско Ромеро в Университете Буэнос-Айреса и в Париже в штаб - квартире ЮНЕСКО, и в Англии по личному приглашению английского историка А. Тойнби. Сам Л. Сеа так вспоминает об этом знаменательном событии: «В том же 1953 г., после визита Тойнби, я был приглашен ЮНЕСКО в свое первое турне по Европе: Франция, Англия и Италия. В Лондоне меня принимал Арнольд Тойнби. В Италии я познакомился с Умберто Компаньоло, основателем Общества
Европейской Культуры», к которому я присоединился как партнер. В Париже я познакомился с Морисом Мерло-Понти из группы Жан-Поля Сартра, с Фернаном Броделем из Сорбонны и многими другими» [5].

В 1953 г. вышла в свет работа Л. Сеа «Америка как сознание» [15], с которой берет начало глобальная проблема всего его творчества: кем является мексиканец / латиноамериканец, и, соответственно, вытекающие из нее проблемы создания собственной уникальной литературы, науки, философии и судьбы культуры в целом; проблемы зависимости и свободы латиноамериканского сознания; проблемы интерпретации истории с точки зрения Латинской Америки.

Таким образом, период 1940-1950-х гг., на который приходится ранний период научно-исследовательской работы Леопольдо Сеа, является одним из самых малоизученных. Тем не менее имеющиеся данные, встречающиеся в автобиографических источниках, позволяют сделать вывод об удивительном соотношении интеллектуальной активности молодого ученого и тех возможностях, предоставляемых послевоенным периодом.

Данный этап демонстрирует принципы складывания единого латиноамериканского интеллектуального сообщества и ту роль, которую сыграл в научном интеграционном процессе Леопольдо Сеа.

\section{ЛИТЕРАТУРА}

1. Pla Leon R. Para un retrato ideologico de Leopoldo Zea // Islas. - 1992. - №103. - Pp. 143-149.

2. Шемякин Я.Г. Межцивилизационное взаимодействие и типы творческой личности / Я.Г. Шемякин // Латинская Америка. - 1997. - №5. - С.62-68.

3. Масалова 0.А. Диалог культур и становление латиноамериканской культурно-исторической идентичности в интерпретации Л. Сеа: диссертация ... кандидата исторических наук : 07.00.09 / Масалова Ольга Алексеевна. - Казань, 2007. - 206 с. (61 07-7/429).

4. Zea L. «Autopercepción intelectual de un proceso histórico»/ L.Zea // Anthropos. Revista de Documentación Científica de la Cultura. 1988. - №89. -P. 11-17.

5. Leopoldo Zea. El Nuevo Mundo en los retos del nuevo milenio [Электронный ресурс]. - URL: https://ensayistas.org/filosofos/mexico/zea/milenio/ (свободный).

6. Маньковская Н.Б. Сеа, Леопольдо // Новая философская энциклопедия в 4-х томах / под ред. В.С. Степина, А.А. Гусейнова, Г.Ю.Семигина, А.П.Огурцова. М.:Мысль, 2000. - Т.3. - 606 с.

7. Dussel E. El Proyecto de una filosofia de la Historia Latinoamericano de Leopoldo Zea / E. Dussel // Vision de America Latina. Homenaje a Leopoldo Zea / complicacion de A.Saladino, A.Santana. - Mexico: Instituto Panamericano de Geografia e Historia, FCE, 2003. - P.21-24.

8. Carrera M. Leopoldo Zea: la filosofia latinoamericana [Электронный ресурc]. - URL: https://cvc.cervantes.es/actcult/zea/acerca/carrera.htm (свободный).

9. Микоян С.А. Несколько слов об авторе и его книге / С.А. Микоян // Сеа Л. Философия американской истории. Судьбы американской истории. - М.: Наука, 1983. - C.8-12.

10. Сеа Л. Предисловие автора / Л. Сеа // Сеа Л. Философия американской истории. Судьбы американской истории. - М.: Наука, 1983. - С.9-12.

11. Biagini H.E. Identidad, Utopia e integracion: el pensamiento alternativo en la Argentina contemporanea. Una propeddutica para elbicentenario / H.E. Biagini // Vision de America Latina. Homenaje a Leopoldo Zea / complicacion de A. Saladino, A. Santana. Mexico: Instituto Panamericano de Geografia e Historia, FCE, 2003. - P.277-287.

12. Кромбет Г.Г. Концепции национальной философии Л. Сеа / Г.Г. Кромбет / Из истории философии Латинской Америки XX века. - М.: Наука, 1988. C.189-203.

13. Zea, L. Mi experiencia en la Secretaria de Relaciones Exteriores [Электронный ресурс] / L.Zea // Cuadernos Americanos, 2003. - №97 // El Nuevo Mundo en los retos del nuevo milenio. - URL: http://www.ensayistas.org/filosofos/mexico/zea/milenio/ (свободный).

14. Zea L. America como conciencia / L. Zea. - Mexico: UNAM, 1953. - 133 p. 